\title{
Individual Vocal Recognition and the Effect of Partial Lesions to HVc on Discrimination, Learning, and Categorization of Conspecific Song in Adult Songbirds
}

\author{
Timothy Q. Gentner, Stewart H. Hulse, George E. Bentley, Gregory F. Ball \\ Department of Psychology, Behavioral Neuroendocrinology Group, Johns Hopkins University, \\ 3400 N. Charles Street, Baltimore, Maryland 21218
}

Received 8 March 1999; accepted 9 July 1999

\begin{abstract}
Among songbirds, the capacity to associate particular songs with particular singers (i.e., vocal recognition) forms the cognitive basis for more complex communication behaviors such as female choice and territoriality. In the present study, we combine operant conditioning techniques and excitotoxic lesions to the forebrain nucleus HVc to examine the role of this region in the discrimination, associative learning, and categorization of conspecific song. We trained adult male and female European starlings, Sturnus vulgaris, to recognize simultaneously the songs of several conspecific males. Then, using a series of transfer procedures, we demonstrate that correct recognition does not generalize to song bouts containing novel motifs from familiar singers. This suggests that starlings do not make use of individually invariant source or filter characteristics for vocal recognition. We then lesioned a portion of $\mathrm{HVc}$ bilaterally with ibotenic acid, and exposed the birds to a
\end{abstract}

series of manipulations testing the discrimination, associative learning, and categorization of conspecific song. The lesions attenuated song production among males, but retention of the basic recognition task (i.e., maintenance of the discrimination) was unaffected. However, when the response contingencies were reversed-as a test of associative learning independent of discrimination-the initial performance and subsequent learning rate were negatively correlated with the size of the HVc lesions. This suggests that HVc plays a role in the formation of associations between a song and some referent. The results of this study are discussed in light of earlier claims regarding the role of $\mathrm{HVc}$ in the perceptual processing of conspecific song. () 2000 John Wiley \& Sons, Inc. J Neurobiol 42: 117-133, 2000

Keywords: birdsong; auditory perception; individual recognition; HVc; excitotoxic lesion
Songbirds birds use their elaborate vocal displays (i.e., songs) to communicate with conspecifics in a variety of different behavioral contexts (Catchpole and Slater, 1995; Kroodsma and Miller, 1996; Ball and Hulse, 1998). Most of our knowledge about the proximate mechanisms underlying this form of vocal

Correspondence to: T. Q. Gentner at the Department of Organismal Biology and Anatomy, The University of Chicago, 1027 E. 57th Street, Chicago, IL 60637

Contract grant sponsor: NSF; contract grant numbers: IBN 9317868, IBN 9514525

Contract grant sponsor: NIH; contract grant number: NS35467

(C) 2000 John Wiley \& Sons, Inc. CCC 0022-3034/00/010117-17 communication comes from studies of the behavioral and neurobiological bases of song production in adult males and song acquisition in juveniles. Comparatively few studies have investigated the proximate mechanisms of song perception in adult birds. One way to study the proximate basis of song perception in a context that draws on the rich behavioral ecology of songbirds is to examine the behavioral and neurobiological mechanisms of individual vocal recognition. The ability to recognize individual conspecifics by their song (or songs) is a prerequisite to many songbased behaviors with important evolutionary consequences, such as female mate choice and male terri- 
tory defense. Thus, it is not surprising that the capacity for individual vocal recognition is one the few constants among this behaviorally polytypic suborder (Stoddard, 1996). Recognition in any context implies two constituent processes-discrimination and association. To recognize individual conspecific males by their song (or songs), receivers must first discriminate among perceptually distinct acoustic events (i.e., different songs), and then associate those distinct events with particular singers.

In the first part of the present study, we continue our ongoing investigation of the proximate behavioral mechanisms that underlie individual vocal recognition among European starlings, Sturnus vulgaris. The results of earlier studies on vocal recognition in this species suggest that starlings attend to at least two features of a song bout when trying to recognize an individual. First, starlings appear to rely heavily on the specific motifs that compose a song bout. Second, starlings attend to the sequence in which those motifs are sung (Gentner and Hulse, 1998). A third possible mechanism for individual vocal recognition is the use of an invariant acoustic feature (or features) among all (or at least some) of the songs from a single individual. Invariant acoustic features may result from individual morphological variation of the source (i.e., the syrinx), or from individual variation (morphological and/or motor) in the filter properties of the production system. These invariant features have also been referred to as voice characteristics (Lambrechts and Dhondt, 1995; Weary and Krebs, 1992). Starlings do not rely on voice characteristics when categorizing single motifs by individual identity (Gentner, 1999). However, voice characteristics may be imbedded at larger levels of male starling song organization. In the present study, we test the idea that starlings use invariant acoustic features at these larger levels to recognize individuals.

In the second part of this study, we use the operant recognition task to examine the role of the song control nucleus $\mathrm{HVc}$ in the perceptual processing of conspecific song. The role of $\mathrm{HVc}$ in song production has been well established through electrolytic lesions (Nottebohm et al., 1976), immediate-early gene expression (Jarvis and Nottebohm, 1997; Kimpo and Doupe, 1997), and electrophysiology (McCasland, 1987; Yu and Margoliash, 1996). Neurons in HVc also show auditory responses to song (Katz and Gurney, 1981; Margoliash, 1983; Margoliash and Konishi, 1985), leading to the suggestion that this region may be involved in production-independent perceptual processing of these signals. Studies of HVc lesioned female canaries are consistent with this last idea. Lesions to $\mathrm{HVc}$ abolish female behavioral prefer- ences for conspecific over heterospecific song (Brenowitz, 1991) and for sexually attractive song phrases over other phrases of conspecific song (Del Negro et al., 1998; Vallet and Kreutzer, 1995). Among female zebra finches, Taeniopygia guttata, in which HVc is small and does not make connections to other song nuclei such as RA, lesions to $\mathrm{HVc}$ have no effect on copulation solicitations. However, lesions of the caudal portion of the ventral hyperstriatum (cHV) adjacent to $\mathrm{HVc}$ effect solicitation behavior in a manner similar to that observed among the HVc lesioned canaries (MacDougall-Shackleton et al., 1998).

In this experiment, we used a well-established operant conditioning procedure (Hulse, 1995; Gentner and Hulse, 1998; Gentner, 1999) to train male and female starlings to recognize simultaneously the songs of several conspecific males. Once they learned this basic recognition task, we examined the putative role of voice characteristics in mediating individual vocal recognition through a series of transfer manipulations in which the subjects were exposed to novel song stimuli. The first set of transfer stimuli contained novel song bouts composed of familiar motifs, and the second set of transfer stimuli contained novel song bouts composed of novel motifs. If starlings can use voice characteristics to recognize individuals, recognition for both sets of transfer stimuli ought to be above chance. Similar stimuli were used in an earlier study of individual vocal recognition (Gentner and Hulse, 1998), but without the level of control over pretesting song exposure and sex of the subject provided here.

Following exposure to both sets of transfer stimuli, $\mathrm{HVc}$ was lesioned bilaterally in a subset of the animals and the birds were exposed to a second phase of operant testing to measure the perceptual effects of the HVc lesion. Following the lesion, the subjects were returned to the basic recognition task and then exposed to two different discrimination reversal manipulations. Retention of the original recognition task required that subjects discriminate among the different exemplars and associate each with a particular response. Retention deficits are, therefore, attributable to either process. In contrast, the first discrimination reversal required that the subjects maintain the discrimination among familiar exemplars but relearn relevant associations. Thus, in the absence of a retention deficit, reversal effects provide a straightforward measure of associative learning processes. The second reversal discrimination required that the subjects transfer newly acquired response contingencies to familiar exemplars, and thus relies on the ability to categorize discriminable stimuli. 


\section{MATERIALS AND METHODS}

\section{Subjects}

Twenty European starlings, 10 males and 10 females, served as subjects for this experiment. Subjects were wildcaught on a farm 30 miles North of Baltimore, during October and November 1997. Prior to the start of the experiment, subjects were housed in large flight cages along with three to five additional birds of the same sex and species. The flight cages were kept in a large mixed-sex, mixed-species aviary in which the photoperiod was synchronized to the natural fluctuations in day length at this latitude. Immediately prior to the start of the experiment in early March, the subjects were moved to individual cages in a separate room, where the photoperiod was held constant at an 11:13-h light/dark cycle. On this light schedule, starlings will maintain a photostimulated physiological condition indefinitely (Dawson et al., 1985). The subjects were held on this schedule for the duration of the experiment ( $\sim 5-6$ months). Subjects had ad libitum access to food and water at all times while on the natural photoperiod. During behavioral testing, subjects were maintained on food restricted diets at $85 \%$ of their ad libitum body weight.

The male starlings used to generate the stimuli for this experiment, and all of the subjects that had been exposed to these songs, were removed from the aviary prior to the introduction of the subjects used in the present experiment. Although we captured these subjects at the same location as those used for the earlier experiments on individual vocal recognition (Gentner and Hulse, 1998), these animals were trapped nearly 2 full years after the original birds had been taken from our field site. Therefore, although it is impossible to guarantee that these animals had no exposure to the stimuli used in this experiment prior to testing, it is unlikely.

\section{Apparatus}

Experimental sessions were conducted inside a sound-attenuating test chamber (IAC Model AC-3, New York, NY) fitted with a custom made operant response panel (see Gentner and Hulse, 1998, for complete description). Three horizontally aligned response buttons (keys) were centered on the panel above a small opening through which food (Purina Start and Grow) was delivered. Two 10-W incandescent lamps indirectly illuminated the test chamber. Stimuli were presented through a speaker (Bose Model 101, Framingham, MA) mounted above and behind the response panel, out of view of the subject. A computer running custom software controlled stimulus presentation, response contingencies, and data collection. Prior to testing, the maximum sound level of the acoustic stimuli inside the test chamber was set at $70 \pm 2 \mathrm{~dB}$ (A) SPL.

\section{Stimuli}

Male starling song has been well described by several authors (Adret-Hausberger and Jenkins, 1988; Eens, 1989; Mountjoy and Lemon, 1995). Males tend to produce song in structured episodes, referred to here as song bouts. Song bouts vary in length both within and among individuals, but follow a generalized phonological pattern that appears to be species typical (Eens et al., 1991). The song bout itself is composed of sequentially patterned multiple note clusters referred to as motifs. Motifs vary in length from roughly 200 to $1000 \mathrm{~ms}$, and the pattern of notes within a given motif is stable among different renditions. More often than not in the course of a bout, a motif is repeated several times before the next one is sung (Adret-Hausberger and Jenkins 1988; Eens et al., 1989). Thus, one can conceptualize a song bout as a sequence of motifs. The number of motifs contained in a bout is a function of the length of that bout, with long bouts containing more motifs (Eens et al., 1989). Repertoire size in male starlings is defined by the total number of different motifs that a male produces, and a single bout rarely if ever contains all the motifs in a given male's repertoire. Thus, it is possible to obtain relatively long continuous segments of song from a single male that do not share common motifs. We made use of this fact when constructing the stimuli for the present experiment.

To generate the stimuli, digital recordings of five male European starlings were made (Gentner and Hulse, 1998). From each of these five males, we sampled continuous segments of song from multiple bouts until we had a pool of 24 exemplars from each male. Each exemplar was 15 ( \pm 0.25$) \mathrm{s}$ long. Sixteen of the 24 exemplars from each male had motifs in common with one another. Eight of these 16 exemplars were designated as baseline stimuli and the other eight were designated as novel song bout stimuli. The eight remaining exemplars (from the pool of 24) had no motifs in common with any of the baseline or novel song bout stimuli; for this reason, they were designated the novel motif stimuli. The stimulus sets used in each of the different behavioral conditions in this study are combinations of these three types of stimuli from the five different males (Table 1). The stimuli are identical to those used in earlier studies of individual vocal recognition in starlings (Gentner and Hulse, 1998; Gentner, 1999). All stimulus manipulation and signal processing was conducted on a microcomputer (Macintosh, Quadra 650, Cupertino, CA) using digital editing software (SoundDesignerII, Didgidesign-Avid, Menlo Park CA).

\section{Procedure: Operant Conditioning}

Discrimination Training. The subjects were trained to work in the operant apparatus through a combination of autoshaping and shaping procedures that represented successively closer approximations to the baseline training procedure (see Gentner and Hulse, 1998, for a full description). The baseline training procedure used a one-interval choice (yes-no) recognition design (Hulse, 1995; Macmillan and Creelman, 1991) in which a stimulus is drawn from one of two classes and the subject's task is to decide to which class it belongs. In the present case, a peck to the center response key initiated a trial by starting the playback of a randomly selected stimulus exemplar. After a 12-s listening interval, but before the stimulus exemplar finished 
Table 1 Stimulus Set Configurations

\begin{tabular}{lll}
\hline \multirow{2}{*}{ Behavioral Condition } & \multicolumn{1}{c}{ Category/Correct Response } \\
\cline { 2 - 3 } Baseline & \multicolumn{1}{c}{ Individual } & Multiple \\
\hline \multirow{2}{*}{ Novel song bout transfer } & $\mathrm{A} 1, \mathrm{~A} 2, \mathrm{~A} 3, \mathrm{~A} 4$ & $\mathrm{~B} 1, \mathrm{~B} 2, \mathrm{C} 1, \mathrm{C} 2$ \\
& $\mathrm{~A} 5, \mathrm{~A} 6, \mathrm{~A} 7, \mathrm{~A} 8$ & $\mathrm{D} 1, \mathrm{D} 2, \mathrm{E} 1, \mathrm{E} 2$ \\
Novel motif transfer & $\mathrm{A} 9, \mathrm{~A} 10, \mathrm{~A} 11, \mathrm{~A} 12$ & $\mathrm{~B} 9, \mathrm{~B} 10, \mathrm{C} 9, \mathrm{C} 10$ \\
& $\mathrm{~A} 13, \mathrm{~A} 14, \mathrm{~A} 15, \mathrm{~A} 16$ & $\mathrm{D} 9, \mathrm{D} 10, \mathrm{E} 9, \mathrm{E} 10$ \\
Combined & $\mathrm{A} 17, \mathrm{~A} 18, \mathrm{~A} 19, \mathrm{~A} 20$ & $\mathrm{~B} 17, \mathrm{~B} 18, \mathrm{C} 17, \mathrm{C} 18$ \\
& $\mathrm{~A} 21, \mathrm{~A} 22, \mathrm{~A} 23, \mathrm{~A} 24$ & $\mathrm{D} 17, \mathrm{D} 18, \mathrm{E} 17, \mathrm{E} 18$ \\
& $\mathrm{~A} 1, \mathrm{~A} 2, \mathrm{~A} 3, \mathrm{~A} 4$ & $\mathrm{~B} 1, \mathrm{~B} 2, \mathrm{C} 1, \mathrm{C} 2$ \\
& $\mathrm{~A} 5, \mathrm{~A} 6, \mathrm{~A} 7, \mathrm{~A} 8$ & $\mathrm{D} 1, \mathrm{D} 2, \mathrm{E} 1, \mathrm{E} 2$ \\
& $\mathrm{~A} 9, \mathrm{~A} 10, \mathrm{~A} 11, \mathrm{~A} 12$ & $\mathrm{~B} 9, \mathrm{~B} 10, \mathrm{C} 9, \mathrm{C} 10$ \\
Reversal-1 & $\mathrm{A} 13, \mathrm{~A} 14, \mathrm{~A} 15, \mathrm{~A} 16$ & $\mathrm{D} 9, \mathrm{D} 10, \mathrm{E} 9, \mathrm{E} 10$ \\
& $\mathrm{~A} 17, \mathrm{~A} 18, \mathrm{~A} 19, \mathrm{~A} 20$ & $\mathrm{~B} 17, \mathrm{~B} 18, \mathrm{C} 17, \mathrm{C} 18$ \\
& $\mathrm{~A} 21, \mathrm{~A} 22, \mathrm{~A} 23, \mathrm{~A} 24$ & $\mathrm{D} 17, \mathrm{D} 18, \mathrm{E} 17, \mathrm{E} 18$ \\
Reversal-2 & $\mathrm{B} 1, \mathrm{C} 1, \mathrm{D} 1, \mathrm{E} 1$ & $\mathrm{~A} 1, \mathrm{~A} 2, \mathrm{~A} 3, \mathrm{~A} 4$ \\
& $\mathrm{~B} 9, \mathrm{C} 9, \mathrm{D} 9, \mathrm{E} 9$ & $\mathrm{~A} 9, \mathrm{~A} 10, \mathrm{~A} 11, \mathrm{~A} 12$ \\
& $\mathrm{~B} 17, \mathrm{C} 17, \mathrm{D} 17, \mathrm{E} 17$ & $\mathrm{~A} 17, \mathrm{~A} 18, \mathrm{~A} 19, \mathrm{~A} 20$ \\
& $\mathrm{~B} 2, \mathrm{C} 2, \mathrm{D} 2, \mathrm{E} 2$ & $\mathrm{~A} 5, \mathrm{~A} 6, \mathrm{~A} 7, \mathrm{~A} 8$ \\
& $\mathrm{~B} 10, \mathrm{C} 10, \mathrm{D} 10, \mathrm{E} 10$ & $\mathrm{~A} 13, \mathrm{~A} 14, \mathrm{~A} 15, \mathrm{~A} 16$ \\
\end{tabular}

Stimulus exemplar patterns and the associated response contingencies (individual or multiple) for the six behavioral conditions in the present study. The pattern for one of the five stimulus sets is shown. Letters indicate the identity of the singer, and numbers refer to different song bout samples from that individual. For each of the four additional stimulus sets, the songs of a different singer (B, C, D, or E) were singled out from those of the four remaining males. For example, changing all the A's to B's, and vice versa, in Table 1 would generate another stimulus set. Each subject was exposed to only one stimulus set, and the distribution of the five stimulus sets was balanced across males and females. Subjects were lesioned after exposure to the combined set, then returned to the combined set following recovery from the surgery.

playing, a single response to either the left or the right key resulted in either positive reinforcement or punishment depending on the key with which that exemplar was associated. Half of the stimuli were associated with the right key and the other half were associated with the left key. Correct responses (e.g., a response to the left key following a stimulus associated with that key) were reinforced with a 2.5-s access to the food hopper. Incorrect responses (e.g., a response to the right key following a stimulus associated with the left key) were punished with a 6-s time-out during which the house lights were extinguished and the food hopper remained inaccessible. The distribution of responses to the left and right keys was therefore dependent upon the extent to which the subjects were capable of recognizing (or learning to recognize) the stimuli presented in this task. Recognition, in this sense, refers both to the active discrimination among different stimulus exemplars and to differential associations formed between each exemplar and the different responses.

The interval between successive trials was $2 \mathrm{~s}$. In the event that a bird failed to respond within $5 \mathrm{~s}$ following the completed presentation of a given exemplar, the trial ended, and the computer waited for a center key peck to begin the next trial. In addition to causing a 6-s time-out, an incorrect response to a playback stimulus initiated a correction trial sequence in which the same exemplar repeated on all subsequent trials until the bird either responded appropriately or not at all. During the first $12 \mathrm{~s}$ of each stimulus presentation responses to the keys had no effect. This 12-s obser- vation period increased the amount of song to which subjects were exposed on each trial, and so helped limit potential response biases based only on the first part of the stimulus. Immediately following the observation period, responses were reinforced as described above.

Baseline Training. Each subject's task in this experiment was to recognize the songs of an individual male European starling among those of four other male European starlings. For example, one subject was reinforced for pecking the left key each time it heard a song from bird A, and for pecking the right key each time it heard a song from either bird B, C, D, or E. Another bird was reinforced for pecking the left key each time it heard a song from bird B and for pecking the right key each time it heard a song from bird A, C, D, or E. In each case, we refer to the key associated with the songs of the single bird as the individual (INDIV) key, and the key associated with the songs from multiple birds as the multiple (MULT) key. Likewise, the songs associated with each key are referred to as INDIV and MULT stimuli, respectively (Table 1). The association of the INDIV and MULT stimuli with either the left or right response key was counterbalanced across subjects. In all, five different stimulus sets were used in training the baseline task (Table 1), but each subject was exposed to only one baseline stimulus set.

Transfer to Novel Song Bout Stimuli. Once a bird had learned the baseline task, such that it responded correctly on 
at least $80 \%$ of the trials in three or more consecutive 64-trial blocks, that bird was transferred to the novel song bout stimuli. During the novel song bout transfer sessions, the baseline exemplars were replaced with the novel song bout stimuli (Table 1). The novel song bout stimuli were drawn from the songs of the same males that we used to generate the baseline stimuli (Table 1), but in most cases were sampled from different song bouts and had many motifs in common with baseline stimuli. Each subject's task remained the same during these transfer sessions (e.g., peck one key each time you hear a song from male A and the other key each time you hear a song from male B, C, D, or E). The subjects were maintained on the novel song bout stimuli for several sessions until performance reached an asymptotic level.

Transfer to Novel Motif Stimuli. Once each subject had again reached asymptotic performance, responding at or above the $80 \%$ correct criterion for three or more blocks of trials with the novel song bout stimuli, that bird was transferred to the novel motif stimuli. For the novel motif transfer sessions, the novel song bout stimuli were replaced with an equal number of novel motif stimuli (Table 1). Again, the singer identities for the novel motif stimuli (and their assignment to either the left or the right key) were exactly the same as that for the baseline and novel song bout stimuli (Table 1). Subjects were maintained on the novel motif stimuli for at least 300 trials.

Transfer to Combined Stimuli. After performance on the novel motif stimuli had stabilized at asymptote-recognition at or above $80 \%$ correct over three consecutive blocks of trials-the novel song bout and baseline stimuli were reintroduced. The basic task of pecking a particular key every time a subject heard a song from a specific male remained the same, but the number of stimuli that were associated with each response was much larger than before. During a single session with the combined stimulus set the subjects were exposed to 48 different stimulus exemplars: 24 from one male, assigned to one key, and 24 (six from each of four other males) assigned to the other key (Table 1). Once each subject's performance had again reached an asymptote (by the above criterion) and they had run $\sim 1000$ trials $( \pm 100)$ with the combined stimulus set, operant testing was temporarily halted so that we could lesion $\mathrm{HVc}$ (see below). Following recovery from this surgical procedure, the subjects were returned to the combined stimulus set for another 1000 trials.

Reversal Learning. After completing 1000 postlesion trials on the combined stimulus set, the subjects were exposed to the first of two reversal conditions. During the first reversal, the subjects were exposed to only 12 of the 24 exemplars in the combined stimulus set and the response contingencies for those exemplars were reversed (Table 1). Those exemplars that had originally been associated with the INDIV key throughout all of the earlier sessions were now associated with the MULT key, and vice-versa. Of the 12 exemplars associated with each response in the first reversal set, four were from the original baseline stimulus set, four were from the original novel song bout set, and four were from the original novel motif set. For those 12 stimuli originally associated with the MULT key, three of exemplars in the first reversal set were from each of the four different males (Table 1). The subjects were maintained on the reversal-1 stimuli for at least 5000 trials, and after that until they had exceeded a performance criterion of $75 \%$ correct on three consecutive blocks of trials. Once these criteria had been met, the subjects were transferred to the second reversal set. Two subjects failed to meet the performance criterion, and so were never transferred to the second reversal set stimuli.

The second reversal set was composed of the remaining 24 exemplars from the combined stimulus set. As with the first reversal set, the response contingencies for the stimuli in second reversal set were reversed from those in the original training (Table 1). The subjects were maintained on the reversal-2 stimuli for $\sim 2000$ trials, after which time the operant conditioning portion of the experiment was terminated. Following the completion of this last operant test, the subjects were returned to the aviary.

\section{HVc Lesions}

Lesions. Following completion of the initial combined set stimulus condition (see Transfer to Combined Stimuli above) 12 animals (six male and six female) received bilateral ibotenic acid lesions to $\mathrm{HVc}$, and the remaining six animals received sham lesions. Two of the original 20 birds did not survive the surgery. Subjects were anesthetized with a $50-\mathrm{mg} / \mathrm{kg}$ dose of secobarbitol $(50 \mathrm{mg} / \mathrm{mL})$ via intramuscular injection, and placed into a stereotaxic apparatus (Kopf, Model 962). A small episiotomy (1-2 mm in diameter) was made dorsal to HVc in both hemispheres, and a glass micropipette attached to a picospritzer (Parker Instrumentation) was lowered into HVc. The lesions were made by slowly injecting $0.5 \mu \mathrm{L}$ of an ibotenic acid solution (Regis; Cat. No. 330401, $10 \mu \mathrm{g} / 1 \mu \mathrm{L}$ dissolved in $0.1 \mathrm{M}$ phosphate-buffered saline). The ibotenic acid solution was injected into each hemisphere over the course of $5 \mathrm{~min}$. After each injection the pipette was left in place for $5 \mathrm{~min}$ to minimize back-flow along the pipette track. Injection of the ibotenic acid was confirmed visually by monitoring the level of fluid in the pipette during injection. The procedure for the sham-lesioned birds was identical to that just described, except that the pipette was filled with physiological saline and no fluid was injected into HVc. Following recovery from the anesthetic, animals were returned to the aviary and allowed ad libitum access to food and water for 1 week. Following this 1-week recovery period, the subjects resumed testing in the operant apparatus.

Lesion Reconstruction. After measuring song output from the males (see below), all of the subjects were sacrificed by rapid decapitation. The brains were quickly removed, frozen on dry ice, and then stored at $-70^{\circ} \mathrm{C}$ until they were sectioned. The fresh-frozen tissue was cut into $40-\mu \mathrm{m}$ coronal sections on a cryostat and thaw-mounted on gelatincoated microscope slides. After mounting, the tissue was 
fixed in a $4 \%$ paraformeldehyde solution, and then Nissl stained with thionin. Volumetric reconstructions were done for $\mathrm{HVc}$ in both hemispheres of the IBO-lesioned and control animals. The volume of $\mathrm{HVc}$ in each hemisphere and overall (average of both hemispheres) was then normalized by dividing by the volume of a control nucleus, Spiriformalis medialis, in the left hemisphere of each animal. The extent of the HVc lesion in each hemisphere for each animal was quantified by comparing the normalized volume for a given $\mathrm{HVc}$ to the corresponding mean normalized $\mathrm{HVc}$ volume (right, left or overall) for the same-sex control animals, and expressed as a percentage of intact HVc. Volume reconstructions were done using a computerized image analysis system that allowed us to examine the tissue at $\times 10$ magnification. Volume estimates of $\mathrm{HVc}$ include the population of Area X-projecting neurons that form a thin strip along the dorsomedial edge of the telencephalon, the so-called para-HVc region (Johnson and Bottjer, 1995). All volume measurements were made by a person blind to each animal's behavioral data.

\section{Song Output}

After all of the subjects had completed the final phase of operant testing (reversal-2), we recorded the males' song to measure the effects of the HVc lesions on song production. Each male (sham and $\mathrm{HVc}$ lesion) was recorded twice over the course of 2 weeks. Recording sessions took place inside the aviary between 9 A.M. and 12 P.M., and each session lasted $\sim 2 \mathrm{~h}$. In most cases, an HVc lesion and sham lesion subject were recorded during the same session. Although all of the subjects had auditory and visual access to one another, they were housed individually. This allowed us to obtain reasonably clear recordings with low background noise from all of the males, while they were under similar environmental conditions.

\section{Statistical Analysis}

All responses in the operant apparatus can be coded as either correct or incorrect, based on the response with which the particular exemplar presented on a given trial was associated and the response that the subject actually made. Data from the baseline training and first two transfer conditions of the operant task were grouped in blocks of 64 trials. Data from the remaining conditions of the operant task were grouped into blocks of 100 trials. Comparisons among means were made using factorial and repeated measures analysis of variance (ANOVA) with the level of significance set at .05 . The repeated measures ANOVA controls for the fact that responses from an individual were not independent across the different conditions, but still allows for comparisons between groups (male and female, or sham and lesion). Data from correction trials and trials on which the subject made no response were not used in any of the analyses presented here. To analyze further any effect of the lesion, we ran simple regressions between the percentage of $\mathrm{HVc}$ lesioned in each animal and measures of performance on each of the different operant conditions postle-

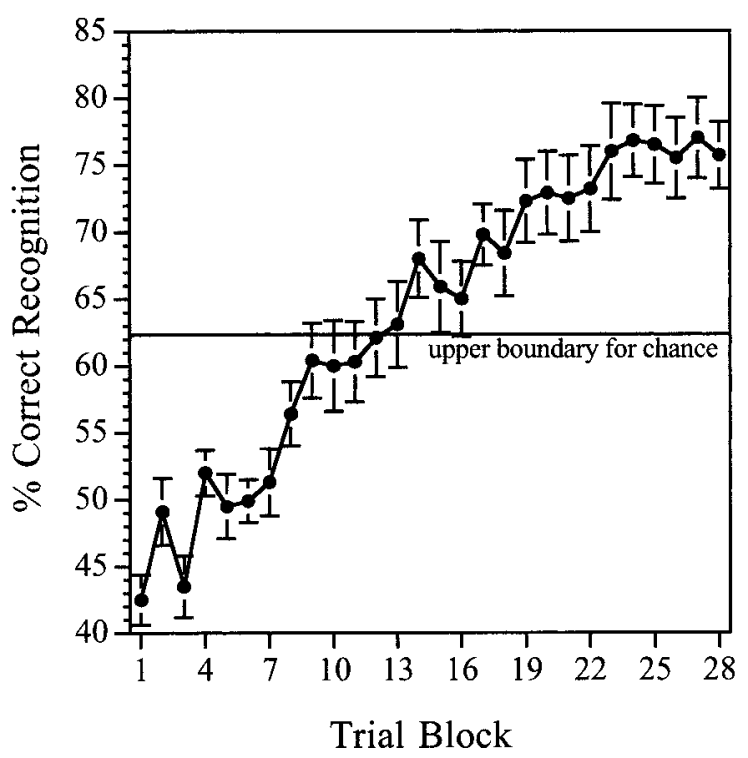

Figure 1 Acquisition curve showing learning during the baseline portion of the operant training. The mean ( \pm S.E.M.) percentage of correct responses pooled across all subjects is shown as a function of the first 28 blocks of trials. Each block contained 64 trials. The upper boundary for the confidence interval around chance is $62.25 \%$.

sion. The significance of each correlation was tested using Fisher's $r$ to $z$ transform. The learning index used to assess each subject's acquisition rate on the reversal-1 condition was the negative exponent of a power law function $T$ $=B N^{-\alpha}$ (Rosenbloom et al., 1988), where $T$ is equal to performance (expressed as the proportion of incorrect trials per block) and $N$ is equal to the number of trial blocks. As performance improves (i.e., the subject learns), the number of errors approaches an asymptote of zero. Thus, the exponent $-\alpha$ is the slope of the learning curve, and so provides an accurate estimate of the acquisition rate. Each subject's data were fit using a least-mean-squares estimate of the error with commercially available software (Prism). The notation "NS" used in the Results section means that the $p$ value associated with a given statistic was $>.05$. All means are shown with corresponding standard errors.

\section{RESULTS}

\section{Prelesion}

Baseline Training. All of the subjects rapidly learned the baseline recognition task. Figure 1 shows the performance (mean percentage of correct responses) over the first 28 blocks of trials (64 trials/ block). The upper boundary for the $95 \%$ confidence interval around chance in a block of 64 trials is $\sim 62 \%$. From Figure 1, one can see that mean performance on the baseline task was significantly above chance by about the 13th block of trials and continued 
to increase thereafter. This change in performance over the first 28 blocks of trials was significant $[F(27$, $513)=27.260, p<.0001]$, further demonstrating the fact that the subjects learned to recognize the baseline stimuli. We observed no significant differences between males and females in the rate at which the baseline task was acquired $[F(1,18)=0.90$, NS]. However, there was a significant difference among the five different baseline stimulus configurations in the pattern of responses across the first 28 blocks of trials $[F(4,15)=5.330, p<.01]$, suggesting that recognition was not acquired at the same rate for each set of baseline stimuli. Post-hoc analyses revealed that the mean performance over the first 28 blocks of trials was significantly higher for one stimulus set (set A) than it was for the other four $(p<.01$ in all cases; Fisher's PLSD). Among the four remaining baseline stimulus sets there were no significant differences (Fisher's PLSD, NS for all comparisons among sets 2-5). All of the subjects eventually learned the baseline task to a high level of proficiency. The mean percentage of correct responses at asymptote was 85.9 $\pm 1.2 \%$. Once performance had reached these asymptotic levels, the earlier differences among the five baseline stimulus configurations were no longer detectable $[F(4,15)=2.352$, NS $]$. There was no significant difference between males and females in the level of correct recognition at asymptote $[F(1,18)$ $=0.340, \mathrm{NS}]$.

Transfer to Novel Song Bout Stimuli. The transfer to the novel song bout stimuli provides a method for testing the generality of the recognition learned in the baseline portion of the task. If subjects continue to recognize accurately the novel song bout stimuli, we have evidence that their behavior in the apparatus is not simply based on the rote memorization of specific stimuli, but rather on more categorical distinctions among classes of different exemplars (Herrnstein, 1990). Recognition during the first session on the novel song bout stimuli remained very accurate. Figure 2 shows the mean levels of performance just before and after the transfer to the novel song bout stimuli. There was a slight but significant drop in the level of correct recognition when comparing performance on the baseline stimuli immediately prior to transfer to that on the novel song bout stimuli just after the transfer $[F(1,10)=5.641, p<.05]$. Although statistically reliable, this drop in recognition was very small, reflecting only $3.6 \%$ points difference (pretransfer mean, $86.0 \pm 1.3 \%$; posttransfer mean, $82.4 \pm 2.0 \%$ ). Even the lower, posttransfer, level of correct recognition is still well above the upper boundary for the $95 \%$ confidence interval around chance. As one can also see from Figure 2, the drop in

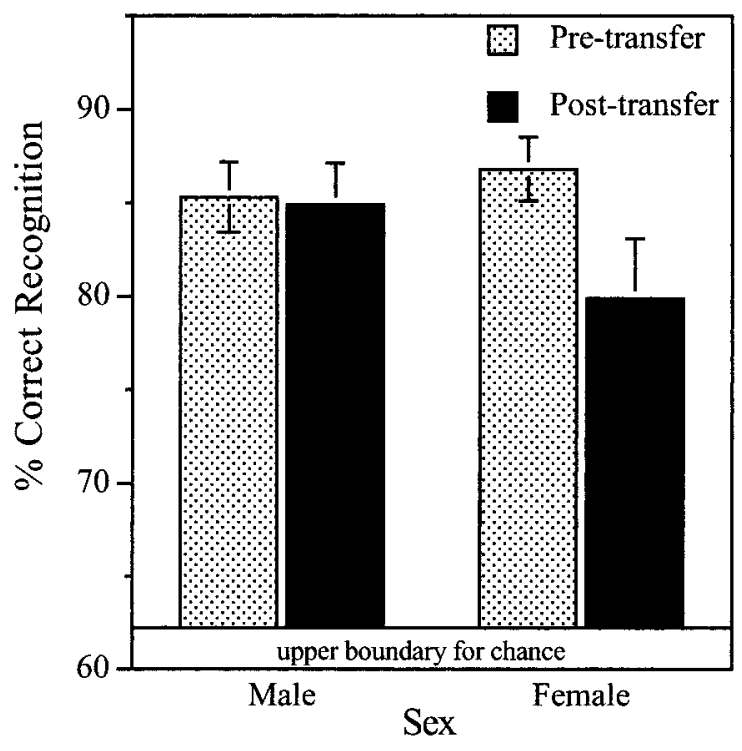

Figure 2 Mean $( \pm$ S.E.M.) percentage of correct responses made over the course of the transfer from the baseline stimuli to the novel song bout stimuli for both males and females. Pretransfer values show means over the five blocks of baseline trials just prior to transfer. Posttransfer values show the mean for the first block of trials only. All blocks contained 64 trials. Note that all values are well above the upper boundary for the $95 \%$ confidence interval around chance.

performance appeared to be restricted largely to the female subjects. The interaction between pre- and posttransfer performance and sex was significant $[F(1,10)=7.794, p<.05]$. As above when means are pooled across sex, female performance following the transfer to the novel song bout stimuli (mean, 79.9 $\pm 3.25 \%$ ) was well above chance. In addition, recognition during this first transfer condition was unaffected by the differences among the five stimulus set configurations. There were no significant differences among the levels of responding among the subjects working with the five different stimulus configurations $[F(4,10)=2.365$, NS $]$, and the interaction between pre- and posttransfer performance and the different stimulus sets was not significant $[F(4,10)$ $=2.063$, NS].

Transfer to Novel Motif Stimuli. The transfer from the novel song bout stimuli to the novel motif stimuli allowed us to examine the extent to which recognition in the present task was tied to the specific motifs composing each bout. Recall that the novel motif stimuli had no motifs in common with either the baseline stimuli or the novel song bout stimuli, but that the same male sang all three sets of bouts. Therefore, if recognition in starlings is affected by invariant 


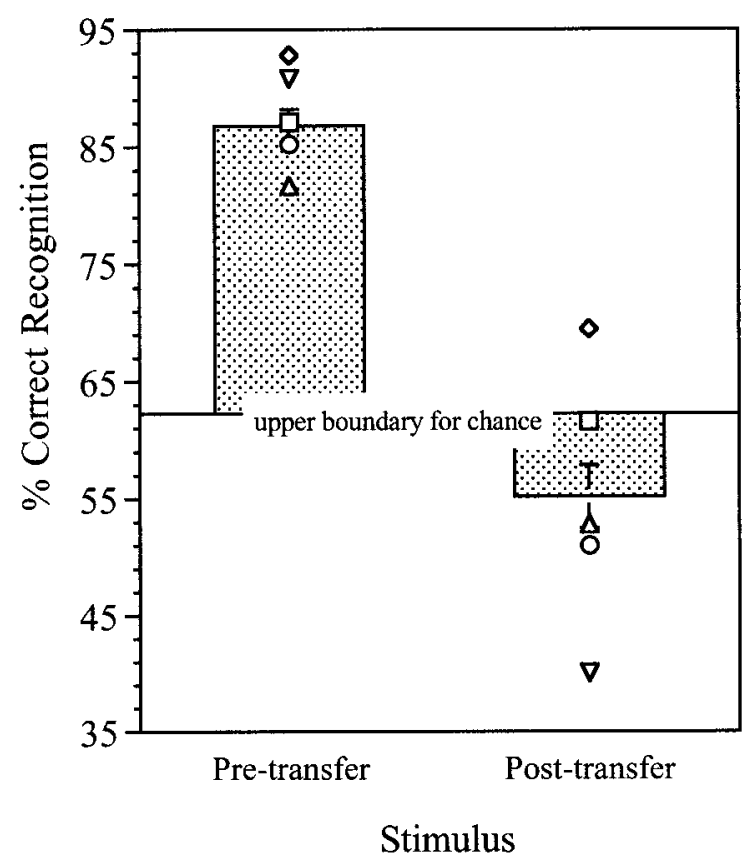

Figure 3 Mean percentages of correct responses made over the course of the transfer from the novel song bout stimuli to the novel motif stimuli. The bars show the means ( \pm S.E.M.) for both pre- and posttransfer trials collapsed across all five stimulus configurations and both sexes. The points show the separate means for each of the five different stimulus configurations (each subject was exposed to only one; Table 1). Pretransfer values show means pooled over the five blocks of trials just prior to transfer. Posttransfer values show the mean for the first block of trials only. All blocks contained 64 trials.

acoustic features that are correlated with individual identity but independent of specific motifs, one would expect recognition to be maintained throughout the transfer to the novel motif stimuli. This was not the case. Recognition failed to transfer from the novel song bout stimuli to the novel motif stimuli. Figure 3 shows the mean levels of performance just prior to and immediately after transfer to the novel motif stimuli. Although recognition was very high prior to transfer, performance dropped dramatically during the first block of trials on the novel motif stimuli. This drop in performance between pre- and posttransfer recognition was significant $[F(1,10)=211.200, p$ $<.0001]$. In contrast to the pattern of results during the first transfer session (novel song bout), correct recognition during the first block of trials with the novel motif stimuli was well within the $95 \%$ confidence interval around chance (mean, $55.2 \pm 2.7 \%$ ) (Fig. 3). There were also differences in the level of recognition among the subjects exposed to the five different stimulus configurations. There was a significant difference among the overall percentage of cor- rect responses made by the subjects working with each stimulus configuration $[F(4,10)=5.467, p$ $<.5]$ and in the magnitude of the drop between preand posttransfer performance associated with each stimulus configuration $[F(4,10)=3.759, p<.05]$. This latter effect appears to be primarily due to the fact that those subjects working with one of the stimulus configurations (set A, Table 1) showed a smaller drop in recognition than did subjects on the other four stimulus configurations (Fig. 3). In fact, the mean percentage of correct responses for this particular stimulus configuration $(69.5 \pm 2.1 \%)$ was above the 95\% confidence interval for chance (Fig. 3). There were no significant differences between males and females in either the overall levels of responding pooled across pre- and posttransfer trials $[F(1,10)$ $=0.832, \mathrm{NS}]$ or in the magnitude of the drop between pre- and posttransfer performance $[F(1,10)=0.054$, NS].

Because the level of correct recognition dropped so sharply upon the transfer to the novel motif stimuli, a significant period of exposure was needed for subjects to reacquire the accurate level of recognition that was seen for the earlier stimulus sets. Figure 4 shows learning during this reacquisition phase. In general, accurate recognition developed in a pattern similar to that observed during the initial baseline training but at a slightly quicker pace. Learning is evidenced by the fact that there was a significant increase in the percentage of correct response made to the novel motif

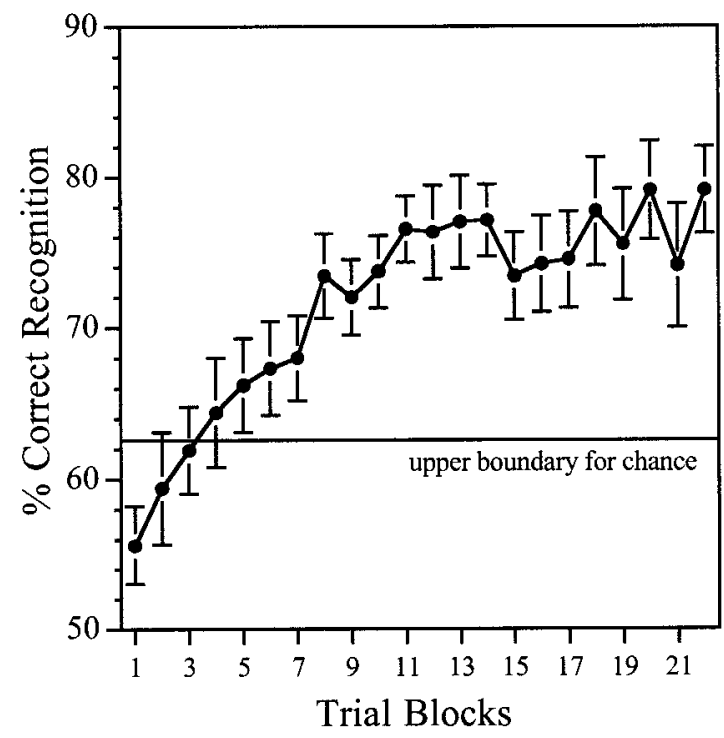

Figure 4 Acquisition curve showing learning during exposure to the novel motif stimuli. The mean ( \pm S.E.M.) percentage of correct responses pooled across all subjects is shown as a function of the first 22 blocks of trials. Each block contained 64 trials. The upper boundary for the confidence interval around chance is $62.25 \%$. 
stimuli as subjects ran more trials $[F(21,399)$ $=8.844, p<.0001]$. As with learning on the baseline stimuli, there was no significant difference between male and females in the overall percentage of correct responses made during the first 22 blocks of trials $[F(1,18)=0.091, \mathrm{NS}]$. Likewise, there was no significant difference in the pattern of correct responses made by males and females over the course of acquisition $[F(21,378)=0.927, \mathrm{NS}]$. In contrast to learning on the original baseline stimulus set, during acquisition of the novel motif stimuli there was no significant difference in the overall level of correct responses made by subjects on the different stimulus configurations $[F(4,15)=2.934$, NS $]$. Similarly, the pattern of correct responses made over the course of acquisition did not differ significantly among the subjects on the different stimulus configurations $[F(84$, $315)=1.211$, NS]. Presumably, the slight increase in acquisition rate over the baseline training reflects an increase in the subjects' skill with the apparatus and knowledge about the general scheme of the recognition task (i.e., peck a key after you hear a song), but may also reflect an increase in the proficiency of the discrimination among different stimulus exemplars.

\section{Histology}

All of the ibotenic acid lesions were directed at $\mathrm{HVc}$ bilaterally. The mean amount of damage to both hemispheres was $44.1 \pm 7.9 \%$ (range, 9.5-83.9\%). Lesions in the left hemisphere tended to be larger than those in the right hemisphere. The mean amount of damage to the left $\mathrm{HVc}$ was $51.1 \pm 8.2 \%$ (range, 12.1-88.9\%). The mean amount of damage to the right HVc was $37.4 \pm 8.8 \%$ (range, $0-79.2 \%$ ). Figure 5 shows typical patterns of the lesions through the rostral caudal plane in two of the subjects with more substantial damage to HVc. In general, the lesions were restricted to the more rostral and dorsal portions of HVc (Fig. 5). Some collateral damage did occur in adjacent structures, including the HVc shelf and bordering caudal neostriatum (NC). In a few cases, there was also damage to the overlying hippocampus, which presumably resulted from back-flow up the injection pathway. Para-HVc-the population of neurons along the dorsomedial edge of the telencephalon adjacent to caudal HVc (Johnson and Bottjer, 1995) was not damaged in any of the lesioned animals. The extent of the collateral damage was not quantified.

\section{Postlesion}

Combined Stimulus Set. Prior to the HVc lesion, the subjects were transferred from the novel motif stimuli to a combined stimulus set that comprised the base-
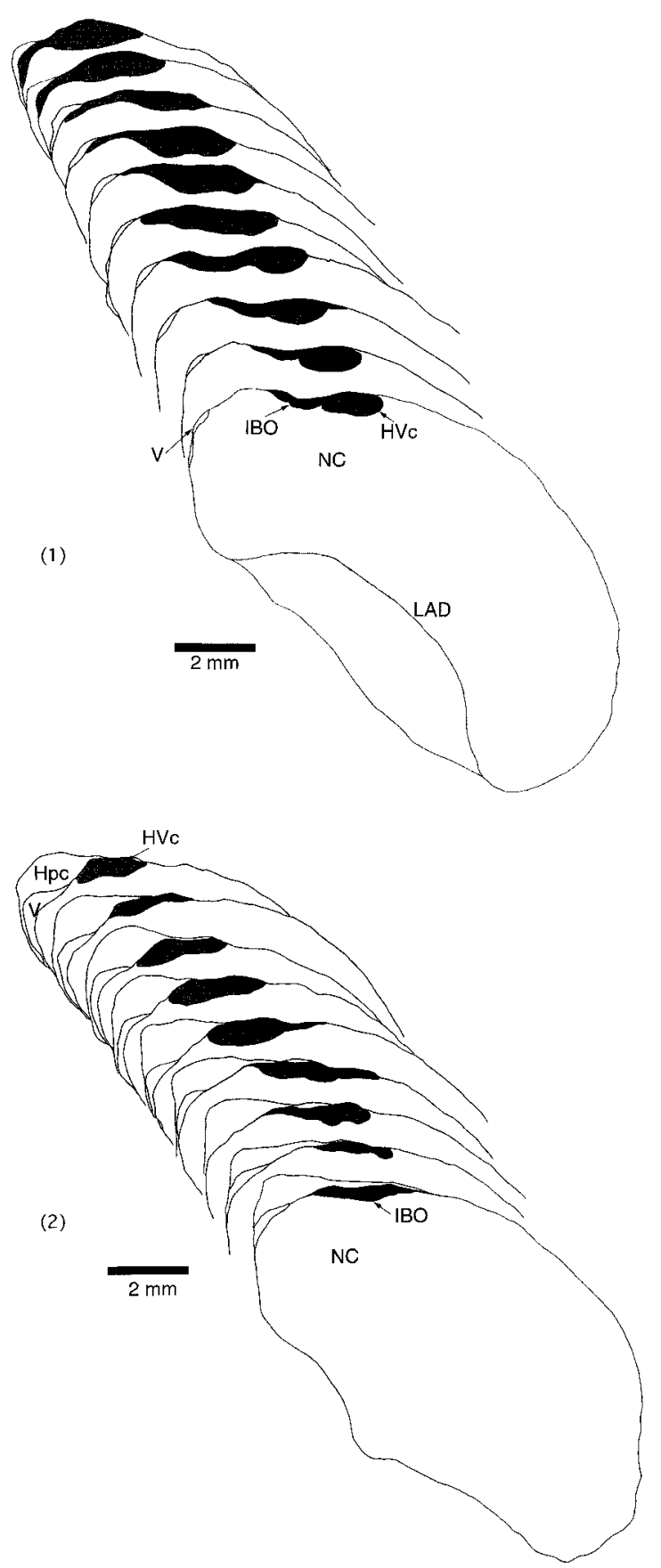

Figure 5 Camera lucida drawings of the ibotenic acid (IBO) lesion in left HVc of two different subjects. Drawings show coronal sections covering $\sim 1 \mathrm{~mm}$ in the rostro-caudal plane with the most rostral section in front. The volume of $\mathrm{HVc}$ for the subject shown in part 1 was equal to $46 \%$ of intact controls, and for the subject shown in part $2 \mathrm{HVc}$ volume was equal to $23 \%$ of intact controls. Hippocampus $=\mathrm{Hpc}$; ventricle $=\mathrm{V}$; caudal neostriatum $=\mathrm{NC}$; dorsal archistriatal lamina $=$ LAD.

line, novel song bout, and novel motif stimuli (Table 1). There was a small but statistically significant drop in performance accompanying this transfer $[F(1,17)$ 
Table 2 Correlation Coefficients between HVc Lesions and Behavior

\begin{tabular}{|c|c|c|c|c|}
\hline & $\begin{array}{c}\text { Combined-Set } \\
\text { Deficit }\end{array}$ & $\begin{array}{c}\text { Reversal-1 } \\
\text { Deficit }\end{array}$ & $\begin{array}{l}\text { Reversal-1 } \\
\text { Learning }\end{array}$ & $\begin{array}{c}\text { Reversal-2 } \\
\text { Deficit }\end{array}$ \\
\hline$\%$ left hemisphere & -0.356 & $0.662 *$ & -0.596 & -0.167 \\
\hline$\%$ right hemisphere & -0.113 & $0.678 *$ & -0.616 & 0.192 \\
\hline$\%$ total & -0.245 & $0.718 *$ & $-0.651 *$ & 0.021 \\
\hline
\end{tabular}

Correlation coefficients between the percentage of $\mathrm{HVc}$ lesioned in each subject (by hemisphere and total) and random variables derived from each of the post-lesion behavioral manipulations. "Combined-Set Deficit" refers to the deficit in recognition performance following reintroduction of the combined stimulus set. "Reversal-1 Deficit" refers to the deficit in recognition performance following transfer to the reversal-1 stimuli. "Reversal-1 Learning" refers to the rate at which the new contingencies associated with the reversal-1 stimuli were learned. "Reversal-2 Deficit" refers to the deficit in recognition performance following transfer to the reversal-2 stimuli.

$* p<.05$, Fisher's $r$ to $z$.

$=7.857, p<.05]$. However, performance on the first block of trials with the combined stimulus set was well above chance (mean percentage of correct responses, $81.6 \pm 2.0 \%$ ). Just prior to time at which the $\mathrm{HVc}$ lesions were made, the mean percentage of correct responses to the combined stimuli, pooled across all the subjects was $84.6 \pm 2.1 \%$. During the first block of trials after the lesions, the mean percentage of correct responses for all the subjects was 74.9 $\pm 2.3 \%$. This difference between pre- and postlesion performance was significant $[F(1,14)=19.386, p$ $<$.001]. Returning the subjects to the same stimulus set after surgical recovery allowed us to test the effect of the HVc lesion on retention of the combined-set recognition. However, as a group the $\mathrm{HVc}$ lesioned animals performed no differently from the sham-lesioned controls. There was no significant difference between the sham and IBO lesioned animals in the overall level of responding averaged across pre- and posttransfer trials $[F(1,14)=2.981$, NS]. More importantly, there was no significant interaction between the IBO and sham-lesioned animals and recognition before and after surgery $[F(1,14)=0.064$, NS]. Including the sex of the subjects in the analysis also yielded no significant effects $[F(1,14)=0.283$, NS, main effect; $F(1,14)=1.212$, NS, interaction with transfer and lesion]. We quantified the extent to which the postsurgical drop in performance was related to the size of HVc lesions among subjects with a simple linear regression between the percentage of HVc lesioned in each subject and the drop in performance for each subject. This correlation was not significant $(r$ $=-0.245$, NS). The results of this regression are shown in Table 2.

Reversal-1. In the preceding manipulation, accurate recognition is dependent on two processes. First, subjects must continue to discriminate among the different combined-set stimuli. Second, they must maintain proper associations between each exemplar and the different response options. Reversing the response contingencies associated with the combined-set exemplars (Table 1) allowed us to dissociate any effects that the HVc lesions had on the discriminative and associative processes that underlie recognition, because only the associative properties of the stimuli were changed. Figure 6 shows the results of the first stimulus reversal. Not surprisingly, there was a dramatic drop in performance accompanying the change in the response contingencies. Prior to switching the response contingencies, the mean percentage of correct responses over the last five blocks of the combined-set stimuli, pooled across all subjects, was 85.7 $\pm 1.6 \%$. After switching the response contingencies, the mean percentage of correct responses over the first block of trials dropped to $27.3 \pm 2.6 \%$. This drop in performance upon reversal was significant $[F(1,14)$ $=232.541, p<.0001]$. Consistent with the notion that discrimination remained intact during the reversal manipulation, correct recognition performance was well below the lower boundary of the $95 \%$ confidence interval around chance $(40.2 \%)$. That is, subjects were correctly discriminating the stimuli, but associating each with the (now) wrong response. Treated as groups, we observed no statistically reliable differences in the magnitude of the drop in performance upon transfer to the reversal-1 stimuli between the $\mathrm{HVc}$ lesion and sham controls $[F(1,14)=0.862, \mathrm{NS}]$. Among the HVc-lesioned animals, however, there was a significant positive correlation between the size of the HVc lesion and the magnitude of the drop in performance following the response contingency reversal ( $r=0.718, p<.05$, [Fig. 7(A) and Table 2].

Given this initial deficit in reversal learning among the HVc-lesioned animals, it is reasonable to suspect that the size of HVc lesions might also affect the rate at which learning occurs over subsequent sessions. Using a power law function (Rosenbloom et al., 1988) (see Materials and Methods) to fit the reversal set-1 learning data from each subject, we generated an index of learning (equivalent to the acquisition rate) for each animal. We then ran a simple linear regres- 


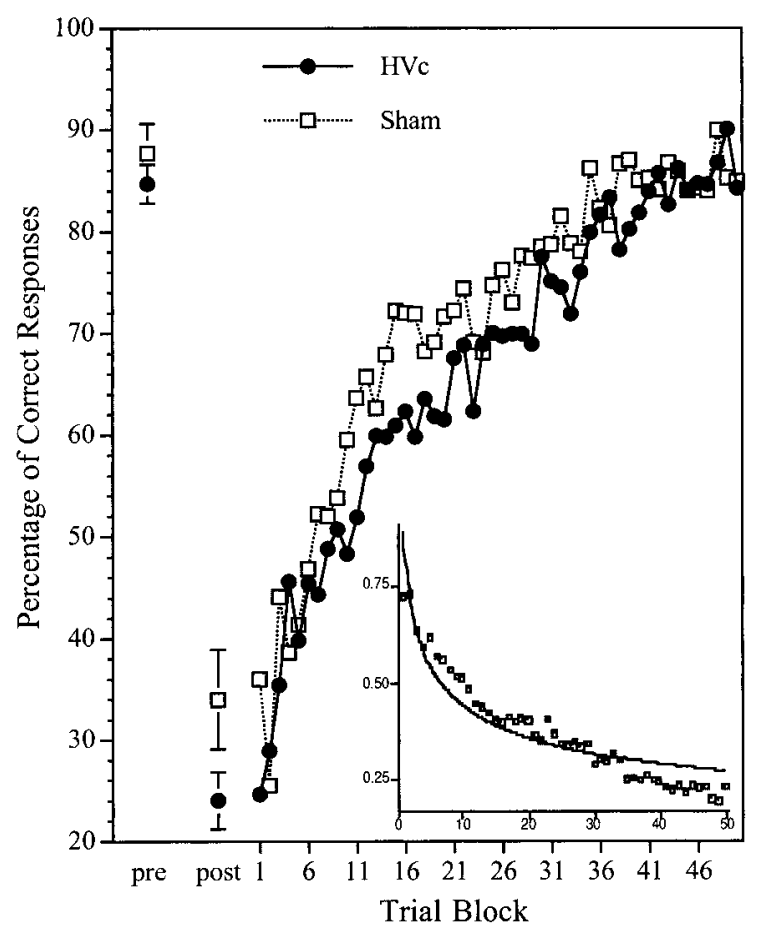

Figure 6 Results of the first response contingency reversal. Data are expressed as the mean ( \pm S.E.M.) percentage of correct responses for HVc- and sham-lesioned groups of subjects. Prereversal means are collapsed over the last five blocks of trials on the combined-set stimuli. Postreversal means show the values for the first block of trials only. Each block contains 100 trials. The inset in the lower right-hand corner shows the mean proportion of incorrect responses as function of stimulus exposure (trial blocks) for all subjects, with a power law function fitted to those data. A similar function was fitted to the acquisition curves of each the subjects to generate the learning index for that bird (see text).

sion between this learning index and the extent of $\mathrm{HVc}$ lesioned in each animal. There was a significant negative correlation between the size of the $\mathrm{HVc}$ lesion and the rate at which subjects learned the reversal-1 task $(r=-0.543, p<.05)$ [Fig. 7(B) and Table 2]. As one can see from Figure 7(B), the larger the lesion to $\mathrm{HVc}$, the longer it took subjects to learn the reversed associations. Consistent with the lack of group effect in the initial performance on the reversal-1 stimulus set, there was no significant difference between the rates at which the sham- and IBO-lesioned birds relearned correct responses to the reversal-1 stimuli $[F(49,784)=0.79, \mathrm{NS}$, interaction among groups in repeated measures ANOVA; $t$ $=0.435, \mathrm{df}=16, \mathrm{NS}, t$ test of mean acquisition rates for each group]. Also, there were no significant effects of sex in any of the reversal- 1 data.

Reversal-2. Recall that only half of the combined-set stimuli were used in the first reversal (Table 1). This allowed us to use the second half of the original combined-set stimuli to test the generality of the new associations formed in the reversal- 1 condition. That is, to the extent that the stimuli were categorized according to individual singer, the associations learned in the reversal-1 condition should transfer to the reversal-2 condition, and subjects should classify the reversal-2 stimuli above chance. As Figure 8 shows, the subjects did recognize the reversal-2 stim-
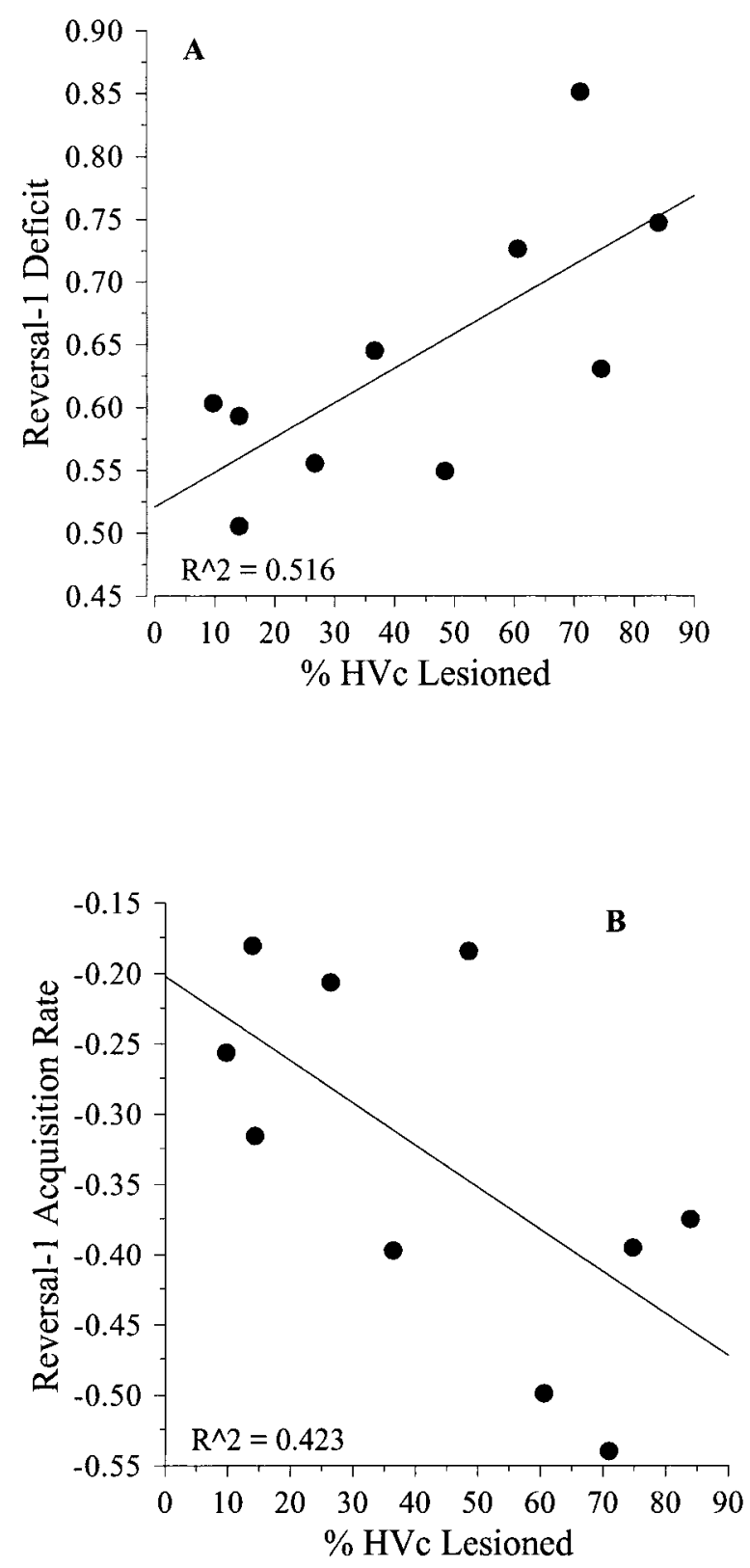

Figure 7 Bivariate scattergrams showing the correlations between the extent of HVc lesioned in each subject, and that subjects performance on the (A) initial reversal-1 discrimination in which the response contingencies were reversed from those in earlier training, and (B) the rate at which these new response contingencies were subsequently learned. 


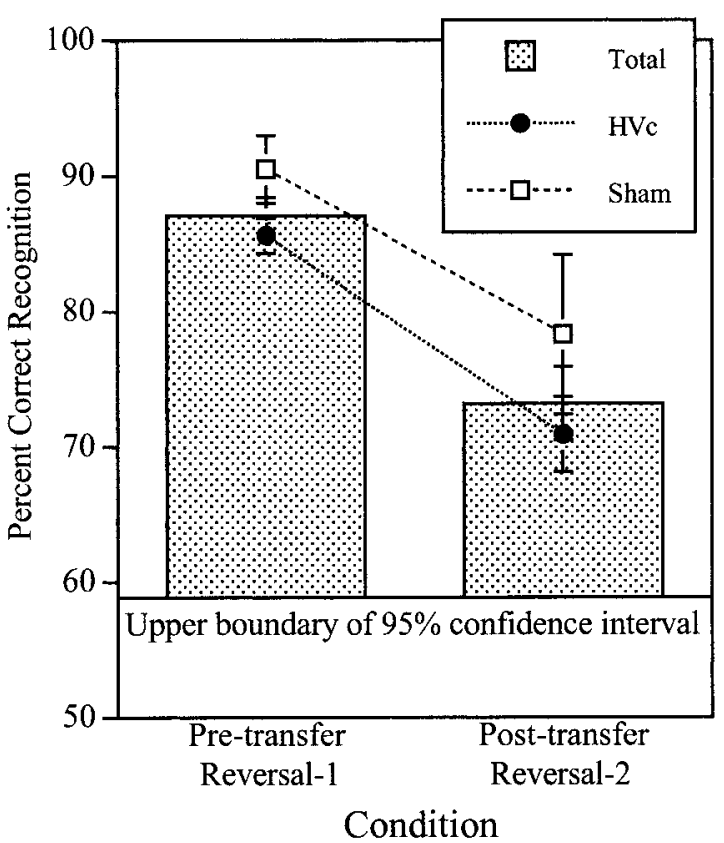

Figure 8 Mean ( \pm S.E.M.) percentages of correct responses made over the course of the transfer from the reversal-1 stimuli to the reversal-2 stimuli. Pretransfer values show means pooled over the five blocks of reversal-1 trials just prior to transfer. Posttransfer values show the mean for the first block of reversal-2 trials only. All blocks contained 100 trials.

uli at a level well above chance on the first block of trials. The mean percentage of correct responses on the last five blocks of the reversal-1 stimuli for all subjects was $87.1 \pm 1.3 \%$. The mean percentage of correct responses during the first block of the reversal-2 stimuli was $73.2 \pm 2.7 \%$. The upper boundary for the $95 \%$ confidence interval in a block of 100 trials is $59.8 \%$, well below the posttransfer level of recognition. Although this slight drop in recognition was significant $[F(1,12)=28.360, p<.001]$, there was no significant difference between the HVc lesion subjects and the sham controls in the magnitude of the posttransfer deficit $[F(1,12)=0.356, \mathrm{NS}]$. Likewise, within the group of $\mathrm{HVc}$-lesioned subjects, the correlation between the extent of the HVc lesion and the drop in recognition upon transfer to the reversal-2 stimuli was not significant $(r=0.021, \mathrm{NS})$. As with the first reversal condition, there were no significant differences between the performance in males and females in the second reversal condition.

\section{Song Output}

As an independent assay of the behavioral effects of the HVc lesions, we measured the song output (over $2 \mathrm{~h}$ ) of each of the males used in this experiment ( $\mathrm{HVc}$ lesion and sham). As shown in Figure 9, the HVclesioned males produced significantly less song during the recording sessions than the sham lesioned males $[F(1,7)=6.351, p<.05]$. Among those males with $\mathrm{HVc}$ lesions, the correlation between the amount of song that each male produced and the extent of $\mathrm{HVc}$ lesion was not significant (right hemisphere, $r$ $=-0.358$, NS; left hemisphere, $r=-0.514$, NS; total, $r=-0.459$, NS).

\section{DISCUSSION}

The results of this experiment add to our knowledge of the proximate mechanisms underlying conspecific song perception in adult songbirds in two important ways. First, the results of the prelesion operant manipulations provide a demonstration of individual vocal recognition in starlings that is inconsistent with the use of voice characteristics. That is, neither individually invariant source nor filter characteristics of a male songs appear to function in vocal recognition. Instead, the results suggest that starlings learn to distinguish among the songs of conspecific males on the basis of shared motifs. Second, the results of the postlesion manipulations suggest that the song control nucleus $\mathrm{HVc}$ is involved in the learning of relevant associations for new and already recognized songs.

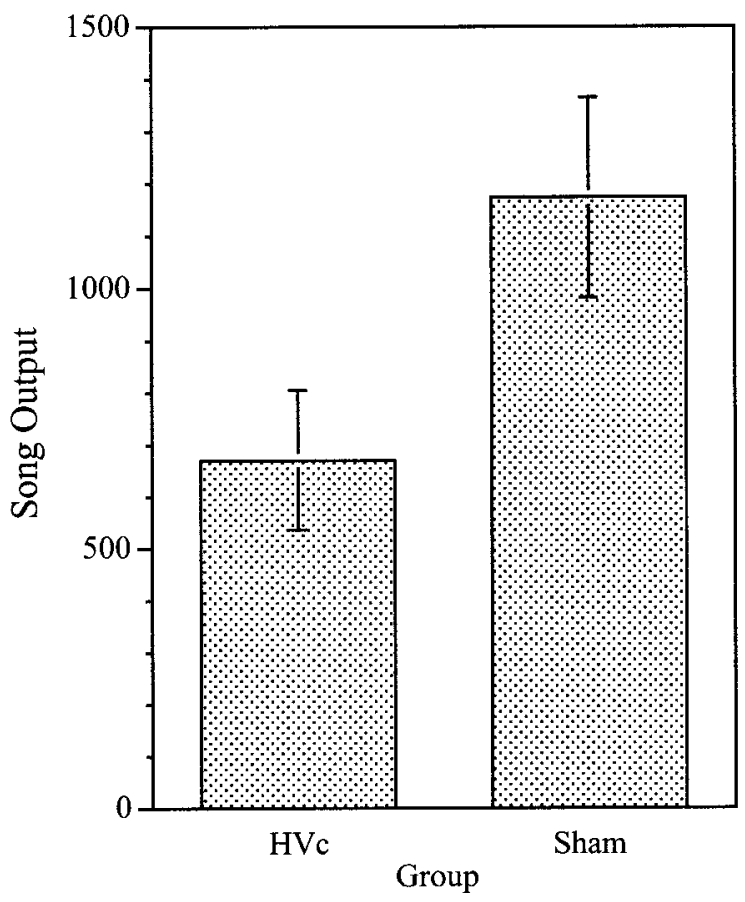

Figure 9 Mean ( \pm S.E.M.) amount of song produced (in seconds) over the course of a 2 -h recording session by males with $\mathrm{HVc}$ lesions and sham lesion controls. 


\section{Individual Vocal Recognition in Starlings}

The first three conditions in this experiment extend our earlier work on the features of song that starlings use for individual vocal recognition. This earlier work demonstrated that both male and female starlings, trained on the same baseline recognition task used in the present study, can transfer accurate recognition to song bouts composed of novel motifs (Gentner and Hulse, 1998). It was unclear, however, from this original study why this accurate recognition had been maintained for the novel motif bouts. One possibility was that the starlings were attending to an invariant acoustic feature (i.e., voice characteristic) in all of the bouts and/or motifs from a single individual. Alternatively, previous exposure to the songs used as stimuli in that experiment might have influenced accurate recognition in the operant apparatus (see discussion in Gentner and Hulse, 1998). All the subjects used in that earlier study, including the males whose songs we used to generate the stimuli for that experiment and the present study, were captured at the same time from the same location. However, the subjects in the present study were taken from our field site over 2 full years after the birds used in that original study, and at a different time of year. Given the average life span and typical migration pattern for European starlings (Feare, 1984), it is extremely unlikely that any of the animals in the present study had previous exposure to the songs used as stimuli. Had the subjects in the present study accurately transferred recognition to the novel motif stimuli, it would still be impossible to unequivocally dissociate the use of voice characteristics and a reliance on previous song experience to recognize song bouts composed of novel motifs. However, this was not the case. Upon transfer from the novel song bout stimuli, initial recognition of the novel motif stimuli was at chance. Therefore, it appears that we provided adequate control for any stimulus preexposure prior to operant training. Most importantly, however, by providing this control we removed any effect on recognition behavior that might be attributable to the use of voice characteristics.

Although there may be invariant acoustic features embedded in the motifs that a given individual sings, these features do not appear to influence individual vocal recognition. This may be an important difference in the mechanisms that birds and humans use to recognize an individual's vocalizations. Among humans, it appears that both source and filter characteristics of the speech production apparatus can contribute to individual talker identification. Individually invariant acoustic features of speech such as vocal timbre and the frequency range of glottal pulsing have long been known to influence individual recognition (Bricker and Pruzansky, 1976; Hecker, 1971). More recent studies using sine wave speech suggest that cues to talker identity are also coded in the idiosyncratic phonetic components of an individual's speech (Remez et al., 1997). Among songbirds, however, the results of earlier studies on the role of voice characteristics in individual vocal recognition have been equivocal. Data from operant discriminations in Great tits, Parus major, were consistent with a role for voice characteristics in individual recognition (Weary and Krebs, 1992). However, subsequent studies investigating the role of voice characteristics have failed to find evidence for their use among either song sparrows, Melospiza melodia (Beecher et al., 1994) or starlings discriminating among motifs (Gentner, 1999). In the latter study, starlings were trained to discriminate among pairs of single motifs, and then transferred to novel motifs from those same singers. Performance on the transfer was no better than chance. Moreover, when transferred to the a different rendition of the training motifs sung by the opposite individual, recognition was reversed. This suggests that motif based discriminations, like the discriminations based on larger song segments in the present experiment, follow the gross phonological structure of each motif and not any individually invariant source or filter characteristics of the signal. Alternatively, one might contend that starlings can use voice characteristics, but that these cues are restricted to some subset of the motifs in an individual's repertoire, and that we simply did not sample from portions of the repertoire that contained these cues. However, given the large number of different stimuli used in the present study, it seems unlikely that all of the motifs in the novel motif song bouts would fall outside this putative subrepertoire.

Based on the results of this experiment, we contend that individual vocal recognition among starlings does not rely on the use of voice characteristics, but rather is dependent on the association of specific song bouts with specific individual males. Because the acoustic distinctiveness of a specific song bout is a function of the different motifs composing that bout, the foregoing contention implies that the motif is the fundamental perceptual unit of individual vocal recognition in starlings. In other words, starlings appear to learn to recognize different conspecific songs by learning to associate specific motifs with specific singers. Subsequent recognition judgments about different song bouts then appear to be made on the basis of whether the motifs composing that bout are associated with a known male. If so, then the song is recognized as one of his. If not, recognition of that song falls to chance. 


\section{Role of HVc in Song Perception}

Recognition in any context implies two constituent processes-discrimination and association. To recognize individual conspecific males by their song (or songs), receivers must first discriminate among perceptually distinct acoustic events (i.e., different songs or motifs), and then associate those distinct events with particular singers. The results of the second half of this experiment do not suggest a role for HVc in the maintenance of recognition among familiar song bouts. If $\mathrm{HVc}$ does play a role in the maintenance of recognition among familiar songs, one would have expected to see some deficit in the retention of this recognition among birds with lesions to HVc. However, this was not the case. Although all of the subjects in the present study showed a slight drop in recognition following surgery, there was no difference in the magnitude of this drop between HVc and sham-lesioned animals. Negative results are, of course, inherently difficult to interpret, and it is possible that even larger lesions are required before one observes deficits in recognition maintenance. However, lesions to $\mathrm{HVc}$ are known to produce deficits in song production among canaries (Nottebohm et al., 1976) and zebra finches (Williams et al., 1992), and the males with $\mathrm{HVc}$ lesions in the present study did in fact produce less song than sham-lesioned males (Fig. 9). Although our effects were not as dramatic as those of Nottebohm et al. (1976) — owing possibly to lesion size and a long recovery time- the observed deficit in song production provides an external behavioral validation of our lesions. We also observed sections of song among the lesioned birds where patterns and motif structure seemed to break down. However, because of the large natural variation in songs within individuals, and the fact that prelesion recordings were not obtained, we were not able to quantify this effect. Although species differences in the behavioral effects of HVc lesions (Williams et al., 1992) make comparisons across species difficult, the effects observed in the present study support the interpretation that our lesions successfully targeted HVc. Thus, the notion that $\mathrm{HVc}$ plays a role in the maintenance of recognition among familiar songs is that less tenable, although by no means impossible.

In contrast to the lack of a retention effect, our lesions did appear to affect the process whereby familiar songs are associated with specific singers. When the response contingencies associated with the songs in the combined stimulus set were reversed, subjects with $\mathrm{HVc}$ lesions tended to perseverate longer on the original response, whereas the shamlesioned animals were able to adjust their responses more quickly [Fig. 6 and 7(A)]. This perseveration effect was observable throughout nearly the entire period of reacquisition for the reversal-1 stimuli, resulting in the fact that learning among the $\mathrm{HVc}$ lesioned birds was retarded [Fig. 7(B)]. Similar reversal deficits without impairment of discrimination retention have been observed following lesions to the prefrontal cortex in rats (Kolb et al., 1974), cats (Irle and Markowitsch, 1984), several species of nonhuman primates (Dias et al., 1996; Iverson and Mishkin, 1970), and humans (Daum et al., 1991). HVc is part of the neostriatum, and in pigeons lesions to the caudolateral neostriatum produce similar reversal learning deficits while leaving visual discrimination tasks intact (Hartmann and Güntürkün, 1998). The data from the present experiment support the conclusion that $\mathrm{HVc}$ plays a role in the associative processing of conspecific song.

Interestingly, lesions to the hyperstriatum also lead to reversal learning deficits on visual discrimination tasks in quail (Stettner and Schultz, 1967), pigeons (Macphail, 1975, 1976), and chicks (Benowitz and Teng, 1973). In these cases, reversal learning appears to be mediated specifically by the nucleus intercalatus of the hyperstriatum accessorium and the hyperstriatum dorsale (Shimuzu and Hodos, 1989), two areas of the visual wulst that receive thalamofugal visual projections. Lesions to the hyperstriatum ventrale appear to have no effect on the rate of reversal learning for visual discrimination tasks (Shimuzu and Hodos, 1989). These results suggest auditory regions in the hyperstriatum of songbirds (e.g., cHV) may play an additional role in the associative processing of song.

Based on the results of the prelesion data in this study, we conclude that starlings recognize the songs of conspecific individuals by attending to the specific motifs that compose each bout. If this is true, one would expect that the role of $\mathrm{HVc}$ in forming associations between different singers and their songs would in essence function to establish associations between specific motifs and the individuals that sing them. The results of the second response contingency reversal are consistent with this idea. Although the $\mathrm{HVc}$ lesioned birds were impaired in their ability to learn in the first contingency reversal, we observed no effect of the HVc lesion upon transfer to the stimuli in the second reversal set (Fig. 8). Recall that the song bouts in the second reversal stimulus set shared many motifs with those in the first reversal stimulus set (Table 1). If subjects had to relearn associations between an entire song bout and a new response in the first reversal, the deficits observed for $\mathrm{HV} c$ lesioned birds in that condition should have reemerged upon transfer to the different song bouts in the second reversal because additional associations would have to be made. On the other hand, if subjects had to relearn 
associations between the motifs composing each bout and a new response in the first reversal condition, the $\mathrm{HVc}$ lesion birds should perform as well as the sham lesion birds upon transfer to the second reversal condition. This is what we observed.

One important caveat to these conclusions is that the extent of damage outside HVc inflicted by our lesions was not quantified. Again, the fact that the IBO-lesioned males sang less than the sham-lesioned males suggests that we were successful in targeting $\mathrm{HVc}$, but does not preclude the possibility that we may have simultaneously damaged adjacent structures. In general, damage outside $\mathrm{HVc}$ appeared to be minimal. In those cases where collateral damage was observed, it was primarily restricted to the immediately adjacent caudal neostriatum and $\mathrm{HVc}$ shelf, or, in a few cases, to the overlying hippocampus. We cannot rule out entirely the possibility that the song production effects of the lesion were due to $\mathrm{HVc}$ damage and that the reversal learning effects were due to collateral damage in adjacent structures, however small. However, given the nonuniform localization of collateral damage, this interpretation seems unlikely. In addition, removing considerably larger portions of $\mathrm{HVc}$ may yield qualitatively different perceptual effects, perhaps creating a deficit in the retention of prelesion recognition. Regardless of what additional effects might be attributable to larger lesions, however, the associative learning effects demonstrated here should be maintained.

The auditory properties of $\mathrm{HVc}$ are not fully understood. Initial findings indicated that $\mathrm{HVc}$ showed robust auditory responses (Margoliash, 1986; Lewicki, 1996), particularly to a bird's own song (McCasland and Konishi, 1981; Margoliash, 1983; Margoliash and Konishi, 1985). Subsequent studies have demonstrated, however, that the auditory responses to bird's own song are substantially diminished or absent in awake behaving animals compared to those under anesthesia (Schmidt and Konishi, 1998). Likewise, the expression of ZENK and c-Fos, two immediate-early genes, occurs in $\mathrm{HVc}$ only during song production, but not song perception (Jarvis and Nottebohm, 1997; Kimpo and Doupe, 1997). Thus, the perceptual role of $\mathrm{HVc}$ in awake-behaving songbirds remains unclear. Our data suggest that $\mathrm{HVc}$ is important in song perception, but only under conditions where the associative properties of a given song are actively changing, such as when learning to associate a song with a new response in the apparatus, but not while familiar associations are maintained. This suggests that electrophysiological responses to song should be observed in HVc, but only when birds are learning about the behavioral contingencies associated with various songs. Testing this hypothesis requires a physiological preparation in which the firing properties of neurons are measured while birds are engaged in the sorts of operant tasks that we have presented here.

Because recognition is based on the association of specific stimuli with specific referents, the associative function of $\mathrm{HVc}$ demonstrated in this study is of obvious importance. In addition, as a cognitive behavior, recognition is likely to serve as the basis for more complex tasks such as mating decisions among multiple males. In this regard, it is interesting to speculate how the associative function for HVc may explain data from copulation solicitation studies in female canaries with HVc lesions. Prior to lesions of $\mathrm{HVc}$, female canaries give a significantly greater number of copulation solicitation displays to the playback of conspecific song than to heterospecific song. After lesions to HVc, however, similar numbers of copulation solicitation displays are elicited by both heterospecific and conspecific songs (Brenowitz, 1991; Del Negro et al., 1998). Based upon these results, some researchers have suggested that $\mathrm{HVc}$ plays an important role in the discrimination of behaviorally relevant conspecific and heterospecific song. The results of the present study are inconsistent with this interpretation of the role that HVc plays in song perception.

Interpreting the results of the female canary lesion studies need not rely on $\mathrm{HVc}$ as the neural locus of conspecific song discrimination. One hypothesized mechanism consistent with the large corpus of literature on female songbird copulation solicitation is that the solicitation response is general and occurs to many different songs. What results in differential numbers of solicitations associated with different songs (i.e., a preference) is that this behavior habituates more quickly to some songs than to others (Searcy, 1992). Accordingly, one could argue that female songbirds do not learn which songs to respond to, but rather, which songs not to respond to. Our own data on female choice in starlings are consistent with the foregoing antihabituation hypothesis, and extend the logic of this mechanism into associative learning contexts (Gentner, 1999). By extension, any neurobiological manipulation that affects the rate at which individuals learn about conspecific song would also be expected to influence the number of copulation solicitations observed in response to different songs. Our results strongly suggest that $\mathrm{HVc}$ is important (perceptually) for the formation of associations among conspecific song. Thus, one could speculate that female canaries with $\mathrm{HVc}$ lesions might give equal numbers of solicitation displays to heterospecific and conspecific song, not because they have trouble discriminating between these songs, but because they have trouble associating differential relevance (i.e., potential mate or not) with each song. 
The work reported here was supported by NSF Grants IBN 9317868 to SH and IBN 9514525 to GB, and NIH Grant NS35467 to GB. The authors thank Michela Gallagher for the use of her microscope and computer equipment, and Robert McMahan for providing valuable technical assistance during pilot lesion studies. Two anonymous reviewers provided valuable criticisms on earlier drafts of the manuscript.

\section{REFERENCES}

Ball G, Hulse S. 1998. Birdsong. Am Psychol 53:37-58.

Benowitz L, Teng EL. 1973. Contrasting effects of three forebrain ablations on discrimination learning and reversal in chicks. J Comp Physiol Psychol 84:391-397.

Brenowitz EA. 1991. Altered perception of species-specific song by female birds after lesions of a forebrain nucleus. Science 251:303-305.

Bricker PD, Pruzansky S. 1976. Speaker recognition. In: Lass NJ, editor. Contemporary issues in experimental phonetics. New York: Academic. p 295-326.

Catchpole CK, Slater PBJ. 1995. Bird song. Cambridge: Cambridge University Press. 248 p.

Daum I, Schugens MM, Channon S, Polkey CE, Gray JA. 1991. T-Maze discrimination and reversal learning after unilateral temporal or frontal lobe lesions in man. Cortex 27:613-622.

Del Negro C, Gahr M, Leboucher G, Kreutzer M. 1998. The selectivity of sexual responses to song displays: effects of partial chemical lesion of the HVc in female canaries. Behav Brain Res 96:151-159.

Dias R, Robbins TW, Roberts AC. 1996. Primate analogue of the Wisconsin card sorting test: effects of excitotoxic lesions of the prefrontal cortex in the marmoset. Behav Neurosci 110:872-886.

Eens M, Pinxten R, Verheyen RF. 1989. Temporal and sequential organization of song bouts in the European starling. Ardea 77:75-86.

Eens M, Pinxten R, Verheyen RF. 1991. Organization of song in the European starling: species-specificity and individual differences. Bel J Zoology 121:257-258.

Feare CJ. 1984. The starling. Oxford: Oxford University Press. 315 p.

Gentner TQ. 1999. Behavioral and neurobiological mechanisms of song perception in European starlings, Sturnus vulgaris. Unpublished PhD manuscript, Johns Hopkins University, Baltimore, MD.

Gentner TQ, Hulse SH. 1998. Perceptual mechanisms for individual vocal recognition in European starlings, Sturnus vulgaris. Anim Behav 56:579-594.

Hartmann B, Güntürkün O. 1998. Selective deficits in reversal learning after neostriatum caudolaterale lesions in pigeons: possible behavioral equivalences to the mammalian prefrontal system. Behav Brain Res 96:125-133.

Hecker M. 1971. Speaker recognition: an interpretive survey of the literature. ASHA monographs \#16, Washington: American Speech and Hearing Association. 103 p.
Herrnstein RJ. 1990. Levels of stimulus control: a functional approach. Cognition 37:133-166.

Hulse SH. 1995. The discrimination-transfer procedure for studying auditory perception and perceptual invariance in animals. In: Klump GM, Dooling RJ, Fay RR, Stebbins WC, editors. Methods in comparative psychoacoustics. Vol. 10. Basel, Switzerland: Birkhäuser Verlag. p 319 330.

Irle E, Markowitsch HJ. 1984. Differential effects of prefrontal lesions and combined prefrontal and limbic lesions on subsequent learning performance in the cat. Behav Neurosci 98:884-897.

Iverson SD, Mishkin M. 1970. Perseverative interference in monkeys following selective lesions to the inferior prefrontal convexity. Exp Brain Res 11:376-386.

Jarvis ED, Nottebohm F. 1997. Motor-driven gene expression. Proc Natl Acad Sci 94:4097-4102.

Johnson F, Bottjer S. 1995. Differential estrogen accumulation among populations of projection neurons in the higher vocal center of male canaries. J Neurobiol 26:87108.

Katz LC, Gurney ME. 1981. Auditory responses in the zebra finch's motor system for song. Brain Res 211:192-197.

Kimpo R, Doupe A. 1997. FOS is induced by singing in distinct neuronal populations in a motor network. Neuron 18:315-325.

Kolb B, Nonneman AJ, Singh RK. 1974. Double dissociation of spatial impairments and perseveration following selective prefrontal lesions in rats. J Comp Physiol Psychol 87:772-780.

Kroodsma DE, Miller EH, editors. 1996. Ecology and evolution of acoustic communication in birds. Ithaca: Comstock/Cornell.

Lambrechts ME, Dhondt AA. 1995. Individual voice discrimination in birds. Curr Ornithol 12:115-139.

Lewicki MS. 1996. Intracellular characterization of songspecific neurons in the zebra finch auditory forebrain. J Neurosci 15:5854-5863.

Macmillan NA, Creelman CD. 1991. Detection theory: a user's guide. Cambridge: Cambridge University Press. 407 p.

Macphail EM. 1975. Hyperstriatal function in the pigeon: response inhibition or response shift. J Comp Physiol Psychol 89:607-618.

Macphail EM. 1976. Evidence against the response-shift account of hyperstriatal function in the pigeon. J Comp Physiol Psychol 90:547-559.

Margoliash D. 1983. Acoustic parameters underlying the responses of song-specific neurons in the white-crowned sparrow. J Neurosci 3:1039-1057.

Margoliash D. 1986. Preference for autogenous song by auditory neurons in a song system nucleus of the whitecrowned sparrow. J Neurosci 6:1643-1661.

Margoliash D, Konishi M. 1985. Auditory representation of autogenous song in the song system of white-crowned sparrows. Proc Natl Acad Sci 82:5997-6000.

McCasland JS, Konishi M. 1981. Interaction between auditory and motor activities in an avian song control nucleus. Proc Natl Acad Sci 78:7815-7819.

Mountjoy DJ, Lemon RE. 1995. Extended song learning in wild European starlings. Anim Behav 49:357-366. 
Nottebohm F, Stokes T, Leonard M. 1976. Central control of song in the canary, Serinus canarius. J Comp Neurol 165:457-486.

Remez RE, Fellowes JM, Rubin PE. 1997. Talker identification based on phonetic information. J Exp Psychol Hum Percept Perform 23:651-666.

Rosenbloom PS, Laird JE, Newell A. 1988. The chunking of skill and knowledge. In: Elsendoorn BAG, Bouma H, editors. Working models of human perception. London: Academic Press. p 391-418.

Schmidt MF, Konishi M. 1998. Gating of auditory responses in the vocal control system of awake songbirds. Nat Neurosci 1:513-518.

Searcy WA. 1992. Song repertoire and mate choice in birds. Am Zool 32:71-80.

Shimuzu T, Hodos W. 1989. Reversal learning in pigeons: effects of selective lesions of the wulst. Behav Neurosci 103:262-272.
Stettner LJ, Schultz WJ. 1967. Brain lesions in birds: effects of discrimination acquisition and reversal. Science 155: 1689-1692.

Stoddard PK. 1996. Vocal recognition of neighbors by territorial passerines. In: Kroodsma DE, Miller EH, editors. Ecology and evolution of acoustic communication in birds. Ithaca: Comstock/Cornell. p 356-374.

Vallet E, Kreutzer M. 1995. Female canaries are sexually responsive to special song phrases. Anim Behav 49: 1603-1610.

Weary DM, Krebs JR. 1992. Great tits classify songs by individual voice characteristics. Anim Behav 43:283287.

Williams H, Crane LA, Hale TK, Esposito MA, Nottebohm F. 1992. Right-side dominance for song control in the zebra finch. J Neurobiol 23:1006-1020.

Yu A, Margoliash D. 1996. Temporal hierarchical control of singing in birds. Science 273:1871-1875. 